\title{
Implantação de Uma Nova Disciplina à Luz das Diretrizes Curriculares no Curso de Graduação em Medicina da Universidade do Estado do Rio de Janeiro
}

\author{
Implementation of a New Course in the \\ Light of the Curricular Guidelines for \\ Undergraduate Medical Education at the Rio \\ de Janeiro State University, Brazil
}

PALAVRAS-CHAVE

- Promoção de saúde;

- Medicina comunitária,

- Ensino;

- Diretrizes

- Educação Médica.

\section{KEY-WORDS}

- Health Promotion;

- Community Medicine;

- Teaching;

- Guidelines;

- Medical Education.

Recebido em: 03/08/2007

Reencaminhado em: 16/12/2007

Aprovado em: 16/12/2007
Fátima Abreu Itikawa

Denise Herdy Afonso Ricardo Donato Rodrigues Marco Antonio Mello Guimarães ${ }^{l}$

\section{RESUMO}

Este estudo teve por objetivo realizar, com base numa pesquisa qualiquantitativa, a primeira análise do processo de implantação da Disciplina de Medicina Integral I (DMI I): "Conceitos e Práticas em Medicina: Introdução à Promoção e à Educação em Saúde". Elaborada com base nas Diretrizes Curriculares que regem o ensino médico, essa disciplina foi integrada à grade curricular da Faculdade de Ciências Médicas da Universidade do Estado do Rio de Janeiro em 2002. O estudo foi sistematizado a partir de um corte transversal no segundo semestre letivo de 2004 com a participação de 75 estudantes (80\% do total de estudantes do primeiro ano de medicina). Os dados foram coletados em dois momentos do curso: inicial (pré-avaliação) e final (pós-avaliação). As questões abordadas nas avaliações consideraram as seguintes temáticas, todas presentes no curso: a crise atual da medicina e estratégias para sua superação; o papel do médico e os fatores influentes no processo de saúde-adoecimento. A média da pontuação na pré-avaliação foi de 3,7 e, na realizada ao final do curso, de 7,8. Na aplicação do teste " $t$-Student" para dados pareados, encontrou-se o indice $p$ $<0,05$. A análise comparativa dos dados pré e pós possibilita averiguar que o conteúdo programático trabalhado na DMI I foi apreendido pelos estudantes em níveis satisfatórios, sinalizando indicadores adequados para a análise de uma nova disciplina no processo de reformulação curricular.

\begin{abstract}
The objective of this study was to analyze the implementation process of the Integrative Medicine Course I (IMC I): "Medical Concepts and Practices: Introduction to Health Promotion and Education". This discipline was elaborated on the basis of the curricular guidelines that rule medical education and integrated into the curriculum of the Faculty of Medical Sciences of the Rio de Janeiro State University in 2002. The present cross-sectional study was conducted in the second semester of 2004 with a sample of 75 students (80\% of first year medical students). Data were collected at two moments: in the beginning (pre-evaluation) end in the end (post-evaluation) of the course. The evaluation focused the following questions all of them approached in the course: the current medical crisis and strategies to overcome it, the role of the doctor and factors influencing the health-disease process. The mean pre-evaluation score was 3.7 and the postevaluation score 7.8. Student's t test resulted in $p<0.05$. The pre and post evaluation scores show that the content of the IMC I course was satisfactorily assimilated by the students and allow concluding that the indicators used for analyzing a new discipline in the curricular reformulation process were adequate.
\end{abstract}




\section{INTRODUÇÃO}

Há muito se discute a inadequação das escolas médicas frente às exigências de uma formação profissional voltada para um atendimento humanizado e coerente com as necessidades de saúde da população.

$\mathrm{O}$ modelo atual de ensino médico tem sua origem em 1910, quando Abraham Flexner sugeriu filiar os hospitais às faculdades de medicina. Como conseqüência dessa aproximação, a produção de conhecimento na área de saúde fragmentou-se em diversas especializações.

Desde então, a consolidação do ensino em bases científicas, centrado na racionalidade anatomoclínica, determinou, como não poderia deixar de ser, uma mudança na prática médica. Essa prática passou a ser direcionada por "um conjunto de elementos estruturais: o mecanicismo, o biologismo, o individualismo, a especialização, a exclusão das práticas alternativas, a ênfase na medicina curativa, a concentração de recursos e a tecnificação do ato médico"1.

"Fundamentos e conceitos anteriores de uma medicina baseada na relação médico-paciente, na escuta dos problemas, no humanismo e na consideração da unidade indissolúvel do corpo e mente foram muitas vezes deixados de lado" ${ }^{\prime 2}$. O ensino se concentrou decisivamente nos hospitais, resultando prospectivamente no atual modelo hospitalocêntrico de assistência médica, sendo este, hoje, o principal cenário das práticas de graduação.

Segundo Boaventura de Souza Santos ${ }^{3}$,

[...] a nova racionalidade científica é também um modelo totalitário, na medida em que nega o caráter racional a todas as formas de conhecimento que não se pautarem pelos seus princípios epistemológicos e pelas suas regras metodológicas. É esta a sua característica fundamental e a que melhor simboliza a ruptura do novo paradigma científico com os que o precedem

Este modelo de medicina científica entra em crise na segunda metade do século 20, quando a ineficiência do mesmo se fez sentir nos crescentes investimentos necessários ao seu desenvolvimento, com uma contrapartida decrescente dos resultados - alto custo e baixa resolubilidade das necessidades de saúde.

Durante vários anos, foram pesquisadas diferentes estratégias para solucionar a inadequação do modelo flexneriano à realidade da saúde. A Conferência Internacional de AlmaAta ${ }^{4}$, ocorrida no Cazaquistão em 1978, resultante deste momento histórico, propôs que o mundo definisse como prioridade a atenção primária, com a meta "Saúde para Todos no Ano 2000".
Em 1988, a Conferência Mundial de Educação Médica trouxe o debate sobre a humanização do atendimento, o abuso da tecnologia, os custos dos serviços e as expectativas da população quanto ao planejamento da saúde, à proteção do meio ambiente e à promoção da saúde ${ }^{5}$.

Destacamos, no contexto histórico brasileiro, o movimento da Reforma Sanitária, que abriu espaço para a construção do Sistema Único de Saúde (SUS) no âmbito nacional. “Esse movimento procurou realizar profundo questionamento acerca do modelo assistencial vigente no país. Propôs-se novo modo de abordar o processo saúde-doença inserido em sua causalidade social"'6. A Constituição Brasileira de 1988 define, então, um sistema público de saúde organizado em rede de serviços, com o objetivo de garantir acesso universal e gratuito a todas as pessoas.

Esta nova política pública de saúde gerou, entretanto, uma expansão da oferta dos serviços hospitalares e um mercado para profissionais de saúde capacitados para a utilização de "tecnologia de ponta", tendência reforçada pelo modelo de ensino vigente.

A formação médica brasileira atual se estruturou com a "mesma base e a mesma lógica da visão científica moderna, racionalista e positivista, imperante em quase todas as áreas do conhecimento no século $20^{\prime \prime 7}$. O predomínio da mediação da tecnologia na relação médico-paciente e "o especialismo e a mercantilização da medicina, em oposição ao primado da visão integral e à humanização nas relações médico-paciente, são temas cravados na história das origens da profissão médica no Brasil"7

Com foco na especialização, atendendo à demanda do mercado e induzido pelas necessidades do uso das tecnologias, o ensino médico evoluiu de forma distorcida na formação dos recursos humanos. "Na prática, esse ensino reduz-se a um processo de transmissão do conhecimento sobre um corpo concebido à semelhança da máquina artificial, suas doenças e respectivos agentes patogênicos, valendo-se para isso de um modelo pedagógico que privilegia a memorização" ${ }^{\prime 8}$.

\section{DIRETRIZES CURRICULARES}

No terreno fértil das mudanças na proposta de organização do sistema público de saúde crescem as idéias de reformulação do ensino médico, consolidadas, após amplo debate, nas Diretrizes Curriculares Nacionais para os Cursos de Graduação em Medicina.

Instituídas pela Resolução CNE/CES no 4 , de 7 de novembro de $2001^{9}$, estas diretrizes constituem orientações para a elaboração dos currículos, estimulando o abandono de concepções antigas, nas quais as grades curriculares diminuíram 
drasticamente as possibilidades de um ensino integrado e relacionado às necessidades de saúde da população. O conceito de saúde e os princípios do SUS, excluídos até então das temáticas anteriores do ensino médico, tornam-se agora elementos fundamentais na construção dos pressupostos básicos no processo de elaboração das mesmas.

As Diretrizes Curriculares têm como objeto: permitir que os currículos propostos possam construir perfil acadêmico e profissional com competências, habilidades e conteúdos, dentro de perspectivas e abordagens contemporâneas de formação pertinentes e compatíveis com referências nacionais e internacionais, capazes de atuar com qualidade, eficiência e resolutividade, no SUS, considerando o processo de Reforma Sanitária Brasileira.

Entre os seus objetivos destacam-se: levar os alunos dos cursos de graduação em saúde a aprender a aprender, o que engloba aprender a ser, aprender a fazer, aprender a viver juntos e aprender a conhecer, garantindo a capacitação de profissionais com autonomia e discernimento para assegurar a integralidade da atenção e a qualidade e humanização do atendimento prestado aos indivíduos, famílias e comunidades.

As Diretrizes Curriculares, resultado da progressão do debate sobre as necessárias mudanças na capacitação médica iniciado na década de 1990, foram, dessa forma, um passo decisivo para o processo de reformulação curricular centrado numa formação generalista, crítica, reflexiva e humanista. A partir de sua homologação, algumas escolas médicas já inseridas no contexto de discussão de novas propostas de ensino aderiram ao processo de transformação curricular.

\section{FACULDADE DE CIÊNCIAS MÉDICAS (FCM)}

Na FCM, escola tradicional no ensino médico do Rio de Janeiro, incorporada à Universidade do Estado do Rio de Janeiro (Uerj) em 1950, a história não foi diferente das demais: no início do século 21 , viu-se obrigada a se adequar às diretrizes curriculares de 2001 surgidas no contexto da crise do ensino médico no País.

A FCM, cuja história prima por iniciativas inovadoras dentro da universidade, acompanhou esse processo de reconstrução do ensino médico, inserindo-se progressivamente na reformulação do currículo da graduação médica. Objetivando uma grade curricular que favorecesse a implementação das Diretrizes Curriculares, algumas disciplinas foram criadas, outras reestruturadas.

Em paralelo, consolidou-se um processo de reforma departamental, já de longa data almejado. A inserção até então da Disciplina de Medicina Integral no Departamento de Medicina Interna - que incluía a Clínica Médica e Especialidades
Clínicas - não era mais condizente com a lógica da organização dos departamentos, tendo em vista que a mesma se orienta por outros pressupostos. Assim, em 2006 foi instituído na FCM o primeiro Departamento de Medicina Integral, Familiar e Comunitária (DMIFC) do Brasil.

\section{DEPARTAMENTO DE MEDICINA INTEGRAL, FAMILAR E COMUNITÁRIA}

No final da década de 1960, em meio aos movimentos renovadores da prática e do ensino médico de então, é criado o Ambulatório de Medicina Integral (AMI) no Hupe/Uerj. Devido ao distanciamento entre o currículo médico e a realidade sanitária, era necessário consolidar, na prática, novas propostas de ensino, acompanhando o movimento preventista já em organização nos Estados Unidos.

Na década seguinte à sua criação, o AMI foi reestruturado para proporcionar ao estudante um aprendizado do raciocínio clínico a partir da atenção ambulatorial, em que a demanda se caracterizava por um perfil de adoecimento distinto daquele observado na prática hospitalar. A relevância dos aspectos biopsicossociais do processo de adoecimento apontava a necessidade de desenvolver novas práticas de abordagem junto ao paciente ambulatorial.

Um trabalho pioneiro, que vez por outra enfrentava a resistência dos setores mais conservadores da universidade, consolidou-se aos poucos e foi assumindo progressivamente novas responsabilidades, culminando com a criação do atual Departamento (DMIFC).

Neste contexto, os docentes do DMIFC, com o apoio da FCM/Uerj e com base nas Diretrizes Curriculares, elaboraram no início deste século uma proposta de três novas disciplinas obrigatórias para a grade curricular do ensino médico desta instituição:

- Disciplina de Medicina Integral I (DMI I): Conceitos e Práticas em Medicina e Promoção e Educação em Saúde - para estudantes do $1^{\circ}$ ano ( $2^{\circ}$ semestre);

- Disciplina de Medicina Integral II (DMI II): Fundamentos da Organização da Atenção à Saúde e do SUS: da atenção primária a uma rede integrada de serviços de saúde - para estudantes do $2^{\circ}$ ano ( $1^{\circ}$ semestre);

- Disciplina de Medicina Integral III (DMI III): Fundamentos da Medicina de Família e da Comunidade e da Medicina Ambulatorial - para estudantes do $2^{\circ}$ ano ( $2^{\circ}$ semestre).

Essas disciplinas, inseridas nos primeiros anos da graduação, quando o ciclo básico é eminentemente teórico, propiciaram a inserção precoce do estudante nos cenários da pratica 
médica e o conhecimento dos fundamentos da organização da atenção à saúde e do SUS, da medicina de família, da comunidade e da medicina ambulatorial.

\section{DISCIPLINA DE MEDICINA INTEGRAL I (DMI I)}

O processo de elaboração da DMI I abrangeu uma série de encontros regulares dos docentes do DMIFC em 2001, nos quais, após ampla discussão, alcançou-se o esboço inicial do curso.

A disciplina foi, então, organizada em quatro módulos temáticos que orientam as aulas e cujos objetivos são:

Parte I - Desenvolver e construir um conceito integral de saúde a partir de uma abordagem biopsicossociocultural;

Parte II - Refletir sobre o processo saúde-adoecimento e fatores intervenientes;

Parte III - Discutir e desenvolver o conceito de educação em saúde;

Parte IV - Desenvolver ações de promoção e educação em saúde.

A ementa da DMI I engloba: "Conceito de saúde-doença. Saúde-doença enquanto processo: fenômeno complexo e dinâmico. Fatores biológicos, psicológicos e socioculturais: ação e interação. Fatores de risco e proteção à saúde. Comportamento de risco. Vulnerabilidade e resiliência. A medicina como ciência. Fundamentos do conhecimento médico. Paradigma anatomoclínico. Paradigma biopsicossocial. Evolução da medicina e da prática médica. O papel do médico e a profissão médica. Humanismo, ética, comunicação e prática médica. Respeito. Empatia. Campo e cenários da prática médica. Ações de Promoção, Proteção e Educação em Saúde".

O primeiro ano de realização desta disciplina foi 2002, com carga horária total de 80 horas, aulas semanais de quatro horas e duração de um semestre letivo. A turma foi dividida em quatro grupos de 23 estudantes cada, com a presença de dois docentes fixos para cada grupo, em diferentes dias e turnos da semana.

A metodologia de ensino inclui atividades teórico-práticas, tais como discussão de casos e situações-problema, leitura bibliográfica (obrigatória e complementar), realização de entrevistas e apresentação de painéis. As aulas se desenvolvem em ambiente com cadeiras móveis, para trabalho integrado com o grupo em círculo.

No quarto módulo, os estudantes desenvolvem, em grupos menores (de cinco a seis alunos), supervisionados pelo grupo de docentes responsáveis, uma atividade prática de Educação em Saúde planejada por eles e voltada a uma população específica, sobre tema relevante para o público-alvo escolhido. No final do curso é realizado um seminário em dois dias, para encontro de todos os grupos e apresentação, para toda a turma, da atividade desenvolvida por cada grupo com as diferentes comunidades.

O sistema de avaliação do desempenho dos estudantes na disciplina congrega três modalidades principais: (1) avaliação dos conteúdos teórico-práticos trabalhados, mediante uma prova discursiva individual com resposta a situações-problema apresentadas; (2) avaliação da atividade de Educação em Saúde desenvolvida em grupo; (3) avaliação conceitual do compromisso e responsabilidade, incluindo presença e participação em todas as atividades executadas.

Desde sua implantação, a DMI I é regularmente avaliada pela equipe docente mediante momentos comuns, semanais, de encontro de todos os docentes da disciplina. Remetendo às Diretrizes Curriculares, o Art. $13 \S 2$ ํㅜㄹ que "o curso de graduação em medicina deverá utilizar metodologias e critérios para acompanhamento e avaliação do processo ensino-aprendizagem e do próprio curso" ${ }^{\prime \prime}$. Desta feita, estamos diante de um curso com bases teóricas bem definidas, porém com uma forma de fazer que necessita adaptação constante e um corpo docente capacitado e inserido nesta dinâmica.

A fim de sistematizar as informações disponíveis e buscar indicadores que apontem o atendimento ou não das metas da DMI I, coletivamente construídas pelos docentes do DMIFC, elaborou-se este estudo para análise inicial do processo de implantação desta disciplina no curso de graduação em medicina.

\section{METODOLOGIA}

Realizou-se um estudo de corte transversal no segundo semestre letivo de 2004 com a turma de estudantes regularmente matriculados no primeiro ano de graduação da FCM/ Uerj (93 estudantes). No primeiro dia de aula da DMI I, antes de qualquer discussão sobre a temática que essa disciplina abordaria, foi aplicado um instrumento de pré-avaliação a todos os quatros grupos da semana, com permissão prévia dos docentes de cada dia.

Inicialmente, foram prestados os esclarecimentos necessários sobre os objetivos da pesquisa, a participação facultativa e a garantia de sigilo aos estudantes presentes. Todos participaram após a leitura e assinatura de um Termo de Consentimento Livre e Esclarecido, não comprometendo, dessa forma, os princípios da bioética.

O instrumento de avaliação aplicado foi construído com o intuito de diagnosticar, no momento de entrada dos estudantes na disciplina, seus conhecimentos sobre os conceitos-chave que seriam discutidos ao longo do curso e que deveriam ser apreendidos pelos estudantes até o final do mesmo (Anexo). 


\section{GRÁFICO 1}

Distribuição da pontuação das pré e pós-avaliações da DMI I dos estudantes do primeiro ano da FCM/UERJ, 2004.

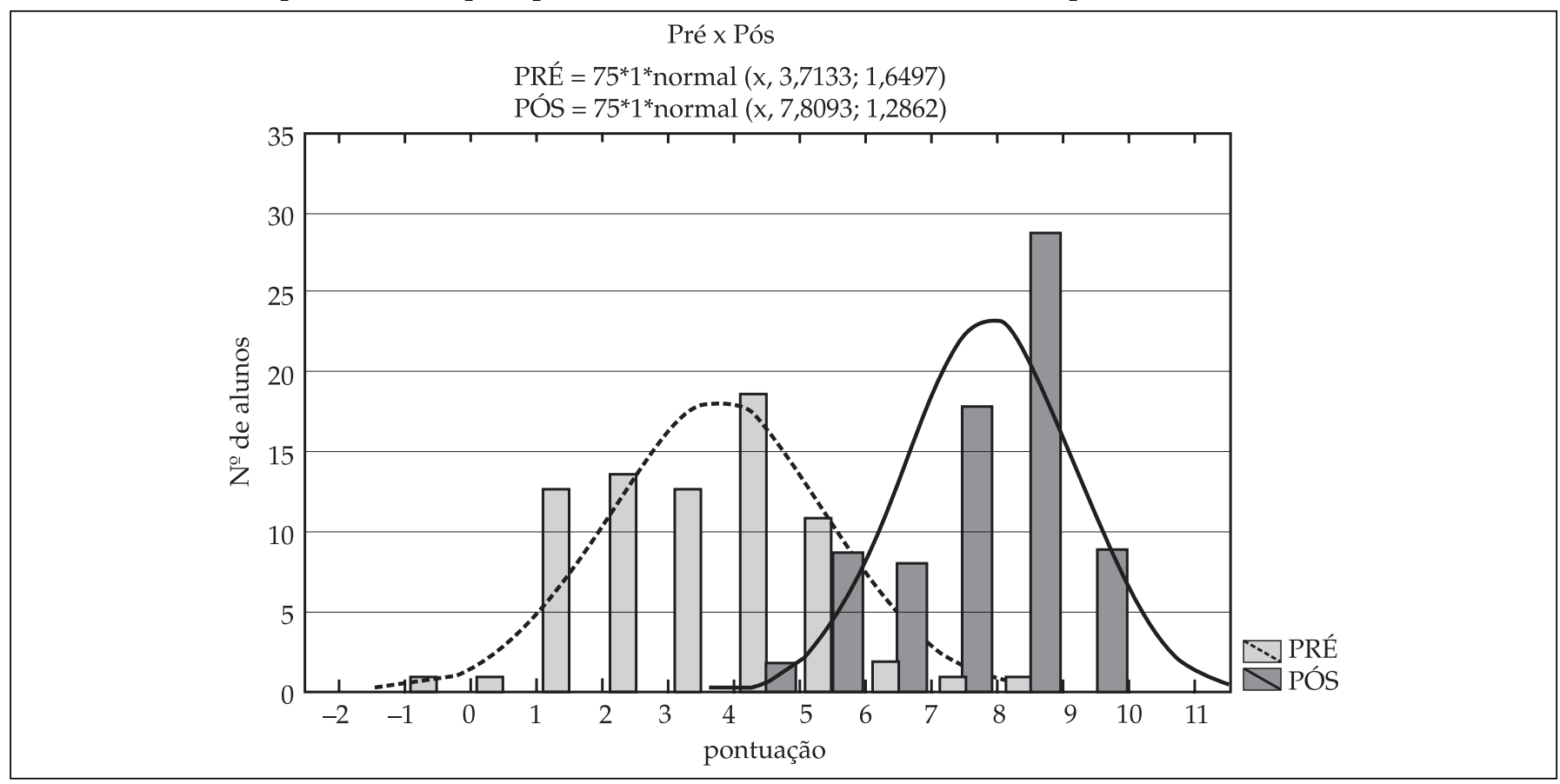

As respostas obtidas nas avaliações foram pontuadas de acordo com uma chave de respostas definida pelos autores deste estudo, baseada num modelo padrão ouro, obtido após a avaliação do instrumento por dois docentes do DMIFC. Conseqüentemente, para cada estudante foi atribuída uma nota de 0 a 10 .

Como mencionado, uma das modalidades de avaliação da DMI I é uma prova discursiva individual, que ocorre ao final do módulo teórico-prático, abrangendo o conteúdo programático trabalhado. Nesta prova (pós-avaliação), foram avaliados os mesmos conceitos abordados no instrumento de pré-avaliação. A correção destas provas foi realizada pelos docentes de cada grupo a partir de uma chave de respostas consensual, obtendo-se também uma nota de zero a dez para cada estudante.

Uma vez levantados, os dados de pontuação dos estudantes participantes foram tabelados como pré e pós-avaliações e submetidos a uma análise comparativa. O teste estatístico utilizado para comparação dos dados pré e pós foi o teste "t-Student" para dados pareados. O intervalo de confiança utilizado foi de $95 \%$, e os valores considerados significativos quando o índice de $p$ era $<0,05$.

\section{RESULTADOS}

O número de estudantes participantes (75) correspondeu a $80 \%$ do total de estudantes do primeiro ano de medicina.
A média da pontuação na pré-avaliação foi de 3,7, sendo que as notas variaram entre 0,0 e 8,3 com CV 44,4\% (coeficiente de variação). Na pós-avaliação, a média da pontuação foi de 7,8, com variação de 4,5 a 10,0 e CV 16,4\%.

No histograma de distribuição da pontuação das pré e pós-avaliações (Gráfico 1), observou-se uma curva de distribuição dos dados próxima de uma distribuição normal. Legitima-se assim o teste estatístico selecionado, pois uma das premissas para sua utilização é que as duas séries de dados sejam amostragens de populações normalmente distribuídas.

Aplicando-se, então, o teste "t-Student" para dados pareados, encontramos um p-valor bem menor do que o nível de significância estabelecido $(p<0,05)$. Dessa forma, pode-se afirmar que a diferença de pontuação entre a pré e a pós-avaliação foi estatisticamente significativa (Gráfico 2).

\section{DISCUSSÃO}

Comparando-se os dados apresentados neste trabalho, após a análise da pré e da pós-avaliação, buscamos identificar se o conteúdo programático trabalhado na DMI I foi apreendido pelos estudantes. Observa-se no Gráfico 2 uma diferença significativa nas médias dessas avaliações.

Como mencionado, a ementa dessa disciplina engloba elementos-chave para a formação profissional do futuro médico. 
GRÁFICO 2

Resultado das pré e pós-avaliações da DMI I dos estudantes do primeiro ano da FCM/Uerj, 2004.

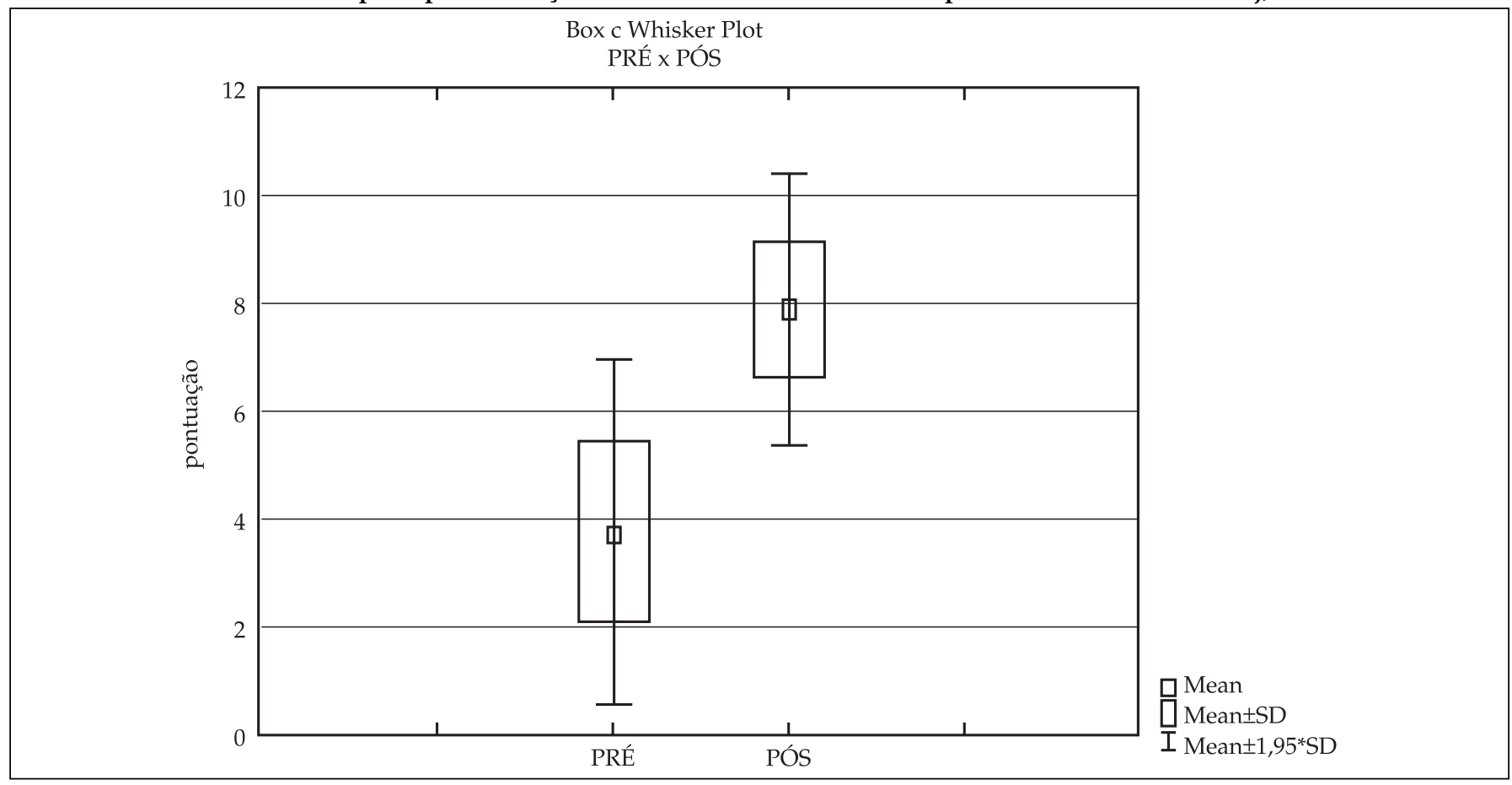

Esses estudantes ingressam na faculdade com expectativas e entusiasmo, e a reformulação curricular baseada nas diretrizes traz uma dimensão ética e humana ao processo de formação acadêmica.

Partindo da compreensão de que a escolha profissional é direcionada por diferentes fatores - oportunidades de mercado, influências do ambiente sociocultural e familiar, identificação de propostas de atuação - , é razoável esperar que estudantes de medicina tenham alguma aproximação com as temáticas da DMI I. Identificar estas interfaces, trabalhar com os preconceitos existentes, redirecionar os debates em função da integração do grupo, estimular a troca entre os diferentes saberes dos estudantes oriundos de realidades sociais diversas são um ponto de partida estratégico para o alcance final dos objetivos da disciplina.

Como preconizado nas diretrizes, a DMI I utiliza metodologias que privilegiam a participação ativa do estudante na construção do conhecimento, o que corrobora um processo de aprendizagem mais abrangente e duradouro.

A metodologia pedagógica tradicional limita os estudantes a memorizar o que ouviram ou leram nas anotações próprias ou alheias, para reproduzir fielmente o que foi apresentado, sem qualquer trabalho de interiorização pessoal ${ }^{10}$.
Novas formas de compreender são necessárias na atualidade, exigindo-se sistemas educacionais inovadores cujo objetivo é fazer com que o estudante aprenda a aprender, efetuando uma revisão contínua dos conhecimentos e valores adquiridos: "a missão primordial do ensino supõe muito mais aprender a religar do que aprender a separar, o que, aliás, vem sendo feito até o presente. Simultaneamente é preciso aprender a problematizar"11.

Além disso, a inclusão de novos cenários, onde as práticas assistenciais estejam ocorrendo e não somente no ambiente hospitalar ou universitário, também favorece essa aprendizagem, enriquecendo com significados distintos o conteúdo trabalhado na disciplina.

Com o objetivo de promover a integração escola-serviço e o conhecimento dos problemas e necessidades da população por parte dos estudantes da primeira série do curso de medicina, um estudo realizado em Londrina $(\mathrm{PR})^{12}$ sinalizou a importância da participação desses estudantes em atividades nas unidades básicas de saúde. De forma similar, outros estudos realizados em nosso país corroboram esses ganhos na formação médica, acrescentando outros, tais como a integração entre teoria e prática, a autonomia e a criatividade no processo de aprendizagem do estudante, o vínculo e a responsabilidade no cuidado e a ampliação da concepção saúde-doença ${ }^{13-16}$. 
A criação de novas disciplinas para os primeiros anos da graduação, com enfoque na promoção e educação em saúde, propicia inserir o estudante precocemente em atividades práticas relevantes para a sua futura vida profissional, permitindo-lhe conhecer e vivenciar situações variadas de vida e incentivando sua interação ativa com usuários e profissionais de saúde desde o início de sua formação. Possibilita, assim, que o estudante assuma responsabilidades crescentes, relacionadas ao cuidado e à promoção de saúde. Relatos de iniciativas semelhantes têm sido apresentados em recentes congressos de educação médica no País ${ }^{17,18,19}$.

Organismos Internacionais, como a Organização Mundial de Saúde (OMS) e a Associação Mundial dos Médicos Gerais e de Família (Wonca), têm evidenciado a importância desses conceitos na formação médica geral, independentemente da especialidade que o futuro médico irá exercer.

Assim como em muitos países desenvolvidos, algumas escolas médicas brasileiras realizam mudanças mais consistentes em seus currículos, baseando-se numa perspectiva ampliada do cuidado em saúde, em contrapartida à hegemonia da medicina tradicional. A ciência clássica trabalha com a idéia de simplificar a compreensão dos fenômenos por meio da separação e da redução, utilizando um enfoque racionalista que se reflete diretamente sobre a forma de ensino da ciência.

Segundo Rodrigues, "o currículo de muitas escolas [médicas] fundamenta-se ainda nos preceitos biológicos de saúde e enfermidades. Gasta-se muito tempo com anatomia, fisiologia e patologia; gasta-se muito tempo com a memorização do corpo e suas lesões" ${ }^{\prime 20}$. Reduz-se o homem e os eventos de saúde e de doença à dimensão biológica, "desvalorizando a diversidade, a singularidade, a interação das diferentes dimensões que compõem o sujeito" ${ }^{21}$.

A medicina científica, assentada na teoria das doenças, "arma-se com uma tecnologia que no primeiro momento limita-se a perseguir lesões e/ou alterações anatomofisiopatológicas; em seguida, alimenta a esperança de removê-las e/ou revertê-las através de intervenções curativas na intimidade do corpo. Portanto, não capta todas as dimensões inerentes ao processo de adoecimento" ${ }^{\prime 22}$. Experiências inovadoras como a inclusão da DMI I na grade curricular da FCM/Uerj foram um passo inicial para reverter esta estreita visão anatomoclínica.

Outro aspecto a considerar no conteúdo trabalhado nesta disciplina é a ênfase dada a que o estudante aprenda, desde o início de sua formação, a escutar as pessoas com quem interage, percebendo a amplitude do processo de saúde-adoecimento para cada indivíduo.

Ensinar o futuro profissional médico a escutar as diferentes linguagens implica necessariamente o comprometimento do professor: cabe a ele ensinar pelo exemplo; identificar linguagens específicas de seus estudantes; promover a troca entre todos; garantir o respeito às diferenças e reescrever a aula a partir da interação com o grupo e seus indivíduos. "Escutar é obviamente algo que vai mais além da possibilidade auditiva de cada um. Escutar, no sentido aqui exposto, significa a disponibilidade permanente por parte do sujeito que escuta para a abertura à fala do outro, ao gosto do outro, às diferenças do outro"23.

É necessário refletir sobre o papel deste professor/orientador/tutor, que neste cenário ocupa um lugar diferenciado daquele até então ocupado: é preciso incluir nas reflexões e práticas das instituições formadoras o espaço para capacitação destes docentes, atores centrais no processo de mudança e, ainda, neste momento, órfãos de ações que privilegiem sua atuação ativa, interativa, participativa em novas disciplinas com novas metodologias e formas de construir o aprendizado.

Estudos anteriores ${ }^{24}$ indicaram a necessidade de maior investimento no corpo docente de forma a aplicar estratégias de ensino mais condizentes com as necessidades e interesses dos estudantes. É necessário desencadear um processo de mudança na formação desses profissionais de modo que os egressos dos cursos aliem as competências técnicas exigidas pelo atual "estado da arte" na área de saúde a valores políticos e sociais ${ }^{25}$.

O educador deve estar comprometido com a busca da transformação e, para isto, precisa ter o conhecimento. Investir no professor é facilitar o processo de mudança. Esquecer esta tarefa é criar resistências, afastar parceiros, atrasar propostas, aprofundar conflitos.

A mudança no ensino médico necessita caminhar lado a lado com a transformação do modelo hegemônico da medicina científica. "O primeiro passo necessário para que a medicina recupere sua verdadeira dimensão social, para que as práticas correspondam às necessidades que se modificam e renovam a cada instante, é tentar superar a instância biológica introvertida; afinal, olhando-se para dentro, não se vê o que está fora" (...) "A medicina da lesão tolhe o poder criativo, sonega o real em sua complexidade; o ensino oferece apenas a imagem inerte do corpo como retrato" 20 .

\section{CONCLUSÃO}

As instituições formadoras têm perpetuado modelos os mais conservadores, centrados na fisiopatologia ou na anatomoclínica, dependentes de procedimentos e de equipamentos de apoio diagnóstico e terapêutico e limitados aos cenários de aprendizagem dos hospitais, incluindo os universitários.

A reforma curricular baseada nas Diretrizes Curriculares trouxe a possibilidade de uma educação dos futuros profissionais orientada para a integralidade tanto da compreensão 
do indivíduo como ser humano possuidor de emoções e sentimentos numa dimensão psicossocial, quanto das ações concretas direcionadas a ele. Mas precisamos considerar que a implantação das Diretrizes Curriculares significa muito mais do que o cumprimento de regras de conduta institucionais. Em sua concepção, elas já apontam as seguintes necessidades: reorganização das práticas educacionais; aprimoramento de metodologias pedagógicas (que permitam a aproximação entre academia e serviços, tendo os estudantes como agentes de transformação); e, especialmente, superação dos limites, impasses e diferenças intra e extra-institucionais que tanto limitam o avanço deste novo paradigma.

O presente estudo demonstra que é possível reconstruir os currículos partindo da prática para a reescritura da teoria; que é indispensável acompanhar o processo de mudança; que é desejável identificar os indicadores de qualidade da educação médica; e que é fundamental reproduzir os modelos de avaliação passíveis de identificação das respostas que tanto buscamos. Dessa forma, espera-se que as questões aqui apresentadas norteiem adequações para um novo ensino, cujo objetivo central seja a compreensão crítica da realidade de saúde, visando à formação de um profissional médico ativo, humano, responsável e ético.

Os estudantes que participaram deste estudo estão atualmente no chamado "ciclo clínico" de nossa instituição e em breve estarão se formando como os médicos que exercerão na prática, conforme se deseja, os conceitos e experiências vivenciados no primeiro ano de graduação na DMI I. Acompanhar esses futuros profissionais, para identificar o quanto a introdução sistematizada desses novos conteúdos contribuiu efetivamente para o alcance do perfil profissional estabelecido nas Diretrizes, é o desafio para os próximos estudos a serem desenvolvidos.

\section{REFERENCIAS}

1. Silva Junior AGda. Modelos tecnoassistenciais em saúde: o debate no campo da saúde coletiva. São Paulo: HUCITEC; 1998.

2. Amoretti R. A educação médica diante das necessidades sociais em saúde. Rev bras educ méd 2005; 29: 136-46.

3. Santos BS. Um discurso sobre as ciências. São Paulo: Cortez; 2003.

4. Conferência Internacional de Alma-Ata. Declaração de Alma-Ata. Cazaquistão; 1978.

5. Rosa AR, Fraga Filho C, Pontes J. Ensino médico: atualidade de uma experiência. Rio de Janeiro: Ed. UFRJ; 1995.

6. Feuerwerker LCM. Mudanças na educação médica e residência médica no Brasil. São Paulo: HUCITEC / Rede Unida; 1998.
7. Lampert JB. Tendências de mudança na formação médica no Brasil: tipologia das escolas. São Paulo: HUCITEC / ABEM; 2002.

8. Rodrigues RD. O papel do hospital universitário no Brasil contemporâneo: dilemas e perspectivas ante o processo de consolidação do SUS. Rio de Janeiro; 1999. Doutorado [Tese] — Instituto de Medicina Social da UERJ.

9. Brasil. Conselho Nacional de Educação. Câmara de Educação Superior. Diretrizes Curriculares Nacionais do Curso de Graduação em Medicina. Resolução CNNE/CES no 4, de 7 de novembro de 2001; Diário Oficial da União. Brasília, 9 nov. 2001; Seção 1, p. 38.

10. Lima-Gonçalves E. Médicos e ensino da medicina no Brasil. São Paulo: Edusp; 2002.

11. Morin E. Educação e complexidade: os sete saberes e outros ensaios. São Paulo: Cortez; 2004.

12. Gonçalves MB, Moraes AMSM. Inserção dos alunos da primeira série do curso de medicina em serviços de saúde. Rev bras educ méd 2003; 27 (2): 83-90.

13. Caetano R, Bassan FB, Silva LA. Avaliação discente de uma experiência curricular: o curso de medicina de família e comunidade para a graduação médica. Anais do $6^{\circ}$ Congresso Brasileiro de Medicina de Família e Comunidade; 2004 abr. 03-06; Rio de Janeiro. Rio de Janeiro: SBMFC; 2004. p. 139.

14. Castro RCL, Breunig M, Streit MB, Thomas PMB, Calvette TF, Campos VJ, et al. Inserção inicial de alunos em atenção primária: um projeto piloto para a disciplina de práticas de atenção à saúde. Anais do $44^{\circ}$ Congresso Brasileiro de Educação Médica; 2006 set. 24-27; Gramado (RS). Rio de Janeiro: ABEM; 2006. p. 40.

15. Cavalcanti SMS, Guimarães F. Aproximação do aluno de primeiro ano à prática médica: descrevendo uma experiência. Anais do $44^{\circ}$ Congresso Brasileiro de Educação Médica; 2006 set. 24-27; Gramado (RS). Rio de Janeiro: ABEM; 2006. p. 60.

16. Ferreira RC, Silva RF, Aguer CB. Formação do profissional médico: a aprendizagem na atenção básica de saúde. Rev Bras Educ Med 2007; 31 (1): 52-9.

17. Pontes ALM, Silva Jr AG, Quintilha J, Koifman L, Saippa G, Pires AC. Considerações sobre a inserção de alunos de graduação na rede básica de serviços de saúde. Anais do $6^{0}$ Congresso Brasileiro de Medicina de Família e Comunidade; 2004 abr. 03-06; Rio de Janeiro. Rio de Janeiro: SBMFC; 2004. p. 140.

18. Silveira R, Leal O, Leal E, Guimarães MH. O ensino da medicina de família e comunidade na graduação: a experiência da Universidade Federal do Acre. Anais do 6º Congresso Brasileiro de Medicina de Família e Comunidade; 2004 
abr. 03-06; Rio de Janeiro. Rio de Janeiro: SBMFC; 2004. p. 143.

19. Gavioli MA, Gonçalves JR, Cyrino AP. A importância da inserção precoce do graduando em medicina na atenção primária à saúde. Anais do $44^{\circ}$ Congresso Brasileiro de Educação Médica; 2006 set. 24-27; Gramado (RS). Rio de Janeiro: ABEM; 2006. p. 44.

20. Rodrigues RD. A crise da medicina: prática e saber - alguns aspectos. Rio de Janeiro; 1979. Mestrado [Dissertação] — Instituto de Medicina Social da UERJ.

21. Deveza M. Saúde para todos: médicos para o ano 2000 ? Rio de Janeiro; 1983. Mestrado [Dissertação] — Instituto de Medicina Social da UERJ.

22. Rodrigues RD, Deveza M, Anderson MIP. Medicina integral: princípios, reflexões e perspectivas. Rio de Janeiro: Faculdade de Ciências Médicas da UERJ; 1998. [mimeo]

23. Freire P. Pedagogia da autonomia: saberes necessários à prática educativa. São Paulo: Paz e Terra; 1998.

24. Santos SC. O processo de ensino-aprendizagem e a relação professor-aluno: aplicação dos sete princípios para a boa prática na educação de ensino superior. Caderno de Pesquisas em Administração 2001; 8 (1): 69-82.

25. Teixeira CF. Ensino da saúde coletiva na graduação. Cadernos ABEM 2004; 1: 20-2.

\section{CONFLITOS DE INTERESSE}

Declarou não haver

\section{ENDEREÇO PARA CORRESPONDÊNCIA}

\section{Fátima Abreu Itikawa}

Universidade do Estado do Rio de Janeiro

Hospital Universitário Pedro Ernesto

Departamento de Medicina Integral, Familiar e Comunitária

Boulevard 28 de Setembro, 77 - 2ªndar

Prédio dos Ambulatórios - Vila Isabel

CEP.20551-900 / RJ

E-mail: faitirj@terra.com.br

\section{ANEXO \\ DISCIPLINA DE MEDICINA INTEGRAL I}

\section{Conceitos e Práticas em Medicina: Promoção e Educação em Saúde}

\section{Pré-Avaliação 2004}

O objetivo desta avaliação é fazer um levantamento inicial sobre o conhecimento do aluno acerca das temáticas que serão abordadas ao longo deste curso. Não fique preocupado, pois a mesma não terá atribuição de nota, sendo somente um instrumento para uso dos professores.

1) Elabore um pequeno texto utilizando as palavras abaixo, relacionando-as à crise da medicina e às estratégias de superação dessa crise:

Reforma Flexner; Paradigma Anatomoclínico; Lesão Orgânica; Doença; Saúde; Curar; Pessoa; Paradigma da Complexidade Biopsicossocial; Corpo; Medicina Integral; Máquina; Tecnologia Industrial; Tecnologia do Cuidado; Intervenção Médica; Custos; Especialização; Iatrogenia.

2) Leia o caso clínico abaixo:

Antonio tem 50 anos, mora no Méier, é casado com Ana há 20 anos, tem dois filhos adolescentes e trabalha como bancário no Centro da cidade. É tabagista de dois maços de cigarro por dia e bebe cerveja nos finais de semana. Há um mês, um colega de trabalho, de 54 anos, teve um infarto do miocárdio e foi submetido a uma cirurgia cardíaca. Antonio, assustado com essa situação, resolveu ir ao médico para fazer uma revisão clínica. O médico, após solicitação de vários exames, verificou que o nível de colesterol estava alto; que o paciente estava acima do peso e que a pressão arterial estava acima dos valores considerados normais, mas que não eram necessários medicamentos no momento. O médico disse a Antonio: "Antonio, as coisas não estão nada boas. Se você não se tratar, corre o risco de ter o mesmo destino do seu colega de trabalho. Você precisa parar de fumar, fazer uma dieta rigorosa, iniciar atividades físicas regulares e se estressar menos". Antonio disse que não tinha tempo para muitas coisas além do trabalho e que fazer dieta era muito difícil, pois comia fora de casa. Parar de fumar ele podia tentar, mas tinha medo de ficar mais nervoso. $\mathrm{O}$ médico disse que ele fizesse o que era necessário, afinal a responsabilidade de seguir o tratamento era do próprio paciente. Marcou uma nova consulta com um intervalo de três meses, pediu novos exames e despediu-se, olhando com freqüência para o relógio, enfatizando que tinha dado as informações de que Antonio necessitava para se tratar e esperava que, na próxima consulta, Antonio trouxesse boas notícias.

Avalie esta consulta, comentando a atitude do médico, como ele agiu visando promover a saúde de Antonio e evitando o risco de doença cardiovascular. Você modificaria algo? $\mathrm{O}$ quê? 